\title{
Electrospun $\mathrm{MgO}$ /Nylon 6 Hybrid Nanofibers for Protective Clothing
}

\author{
Nattanmai Raman Dhineshbabu ${ }^{1}$, Gopalu Karunakaran ${ }^{1}$, Rangaraj Suriyaprabha ${ }^{1}$, Palanisamy
} Manivasakan $^{1}$, Venkatachalam Rajendran ${ }^{1, *}$

(Received 20 October 2013; accepted 11 December 2013; published online 06 January 2014)

\begin{abstract}
Magnesia ( $\mathrm{MgO})$ nanoparticles were produced from magnesite ore $\left(\mathrm{MgCO}_{3}\right)$ using ball mill. The crystalline size, morphology and specific SSA were characterized by X-ray diffraction analysis, transmission electron microscopy and Brunauer-Emmett-Teller method, respectively. MgO nanoparticle-incorporated nylon 6 solutions were electrospun to produce nanofiber mats. Surface morphology and internal structure of the prepared hybrid nanofiber mats were examined by scanning electron microscopy and high-resolution transmission electron microscopy, respectively. The fire retardancy and antibacterial activity (Staphylococcus aureus and Escherichia coli) of coated fabrics made from $\mathrm{MgO} /$ nylon 6 hybrid nanofiber are better than those from nylon 6 nanofiber.
\end{abstract}

Keywords: $\mathrm{MgO} /$ nylon 6 hybrid nanofibers; Cotton fabrics; Fire retardancy; Antibacterial activity

Citation: Nattanmai Raman Dhineshbabu, Gopalu Karunakaran, Rangaraj Suriyaprabha, Palanisamy Manivasakan and Venkatachalam Rajendran, "Electrospun MgO/Nylon 6 Hybrid Nanofibers for Protective Clothing", Nano-Micro Lett. 6(1), 46-54 (2014). http://dx.doi.org/10.5101/nml.v6i1.p46-54

\section{Introduction}

Nanostructured materials such as nanowires, nanorods, nanospheres, and nanofibers are gaining popularity among polymer researchers and industrialists because of their excellent functional properties in textile applications $[1,2]$. Nanometal oxides incorporated into textile fabrics can improve their multifunctional properties such as flame retardancy, UV protection, self-cleaning, antistatic and antimicrobial activities [3]. Although polymeric materials used in textile fabrics can enhance their functional properties, polymeric nanofibers were used as a protective barrier on the textile fabrics for many applications such as wound dressing, air filteration, tissue scaffold, sensors, and fire retardancy [4-7].

Nanofibers have been generally produced through nanospider technology adapted in electrospinning technique [5]. Electrospinning is one of the simplest and most versatile methods to fabricate nanofibers with high specific surface area (SSA) and high porosity [5]. The electrospun nanofibers with superior properties were obtained by controlling the diameter (100-1000 $\mathrm{nm}$ ) and distribution of the fibers $[4,5]$. The complex architectures, for example, core-shell, porous and hollow structures, were formed through incorporation of nanoparticles into fibers and polymer blends [8-11]. Recently, organic/inorganic hybrid materials have shown remarkable performance in multifunctional, mechanical, and physical properties for nanofibers $[12,13]$.

Attempts have been made to incorporate nanoparticles into spun fibers to enhance their properties such as fire retardancy and antimicrobial activities. Polymers, for example, polyamide (PA), polyvinyl alcohol (PVA), polyurethane (PU), polypropylene (PPy), and their composites had been treated to enhance the flame retardancy of fabrics [14]. The biodegradable polyelectrolytic nylon 6 is one of the unique polymer materials widely used in textile industries due to its high mechanical, antimicrobial, thermal, and physical proper-

\footnotetext{
${ }^{1}$ Centre for Nano Science and Technology, K. S. Rangasamy College of Technology, Tiruchengode 637215, Tamil Nadu, India

*Corresponding author. E-mail: veerajendran@gmail.com
} 
ties [15]. Extensive studies have also been carried out to understand the physical, mechanical, and thermal properties of PA or nylon 6 embedded with nanoparticles such as $\mathrm{MgO}, \mathrm{SiO}_{2}, \mathrm{TiO}_{2}, \mathrm{ZnO}$, and $\mathrm{ZrO}_{2}[16,17]$. Similarly, nanometal oxides were incorporated as an additive to polymer matrix and used for multifunctional textile applications such as flammability, UV protection, and antibacterial activities [17]. Among these nanometal oxides, $\mathrm{MgO}$ nanoparticles are of great interest because of their excellent thermal conductivity, heat resistance, and antimicrobial properties. Generally, $\mathrm{MgO}$ nanoparticles were fabricated via chemical methods such as sol-gel, sonication, and flame spray pyrolysis [18-20]. Their composites with polymer matrix were found to improve the mechanical strength and stiffness of the nonwoven fabrics, etc [21].

This investigation is aimed to synthesize and characterize the $\mathrm{MgO}$ nanoparticles from natural resource (magnesite ore) and to incorporate the particles into nylon 6 nanofibers. The functional properties, such as flame retardancy, of $\mathrm{MgO} /$ nylon 6 hybrid nanofibers coated on cotton fabrics, and their antibacterial activities against Staphylococcus aureus and Escherichia coli, were explored.

\section{Experimental section}

\section{Materials}

The natural mineral of magnesite ore $\left(\mathrm{MgCO}_{3}\right.$; Salem, Tamil Nadu, India), nylon $6\left(\left(\mathrm{C}_{6} \mathrm{H}_{11} \mathrm{NO}\right)_{n}\right.$; Sigma 99.9\%, MW: $113.16 \mathrm{~g} / \mathrm{mol}$ ), formic acid (Merck, 99.9\%), and acetic acid (Merck, 99.9\%) were used for the production of $\mathrm{MgO}$ nanomaterials. The horizontal electrospinning apparatus, which consists of a plastic syringe positioned horizontally with its metal needle, a specifically controlled syringe pump (Cole-Parmer, USA), a high-voltage power supply capable of $0-50 \mathrm{kV}$ (Best Mech, India), and rotating grounded collector, was used to produce the nanofibers.

\section{Synthesis and characterization of $\mathrm{MgO}$ nanopar- ticles}

Soft aggregates of calcined $\left(600^{\circ} \mathrm{C}\right)$ magnesia $(\mathrm{MgO})$ samples were prepared by mechanical grinding (PM100; Retsch, Germany) in dry state (shown in Fig. 1). The samples containing $5 \mathrm{~g} \mathrm{MgO}$ microparticles were placed in the zirconia grinding container with a protective jacket and ground with 20 balls at $500 \mathrm{rpm}$ for $3 \mathrm{~h}$. After milling, the particles were collected and dried for $1 \mathrm{~h}$ in vacuum.

The samples were characterized by X-ray diffraction (XRD; X'Pert PRO; PANalytical, Almelo, the Netherlands) spectrometer using $\mathrm{CuK} \alpha$ as a radiation source $(\lambda=0.1560 \mathrm{~nm})$. The average crystallite size of $\mathrm{MgO}$ particles was determined by the Scherrer formula [22]. The SSA of the particles was measured on BrunauerEmmett-Teller (BET) SSA analyzer (Autosorb AS1MP; Quantachrome, Boynton Beach, FL). The sample was degassed for $3 \mathrm{~h}$ at $295^{\circ} \mathrm{C}$ and then performed with $\mathrm{N}_{2}$ adsorption measurements at liquid nitrogen temperature. The as-prepared $\mathrm{MgO}$ nanoparticles were dispersed in water media at a concentration of $0.1 \mathrm{wt} \%$ and ultrasonic treated for $5 \mathrm{~min}$. The particle size distribution was measured by dynamic light scattering technique using Particle Size Analyzer. The morphology and primary particle size of the nanoparticles were

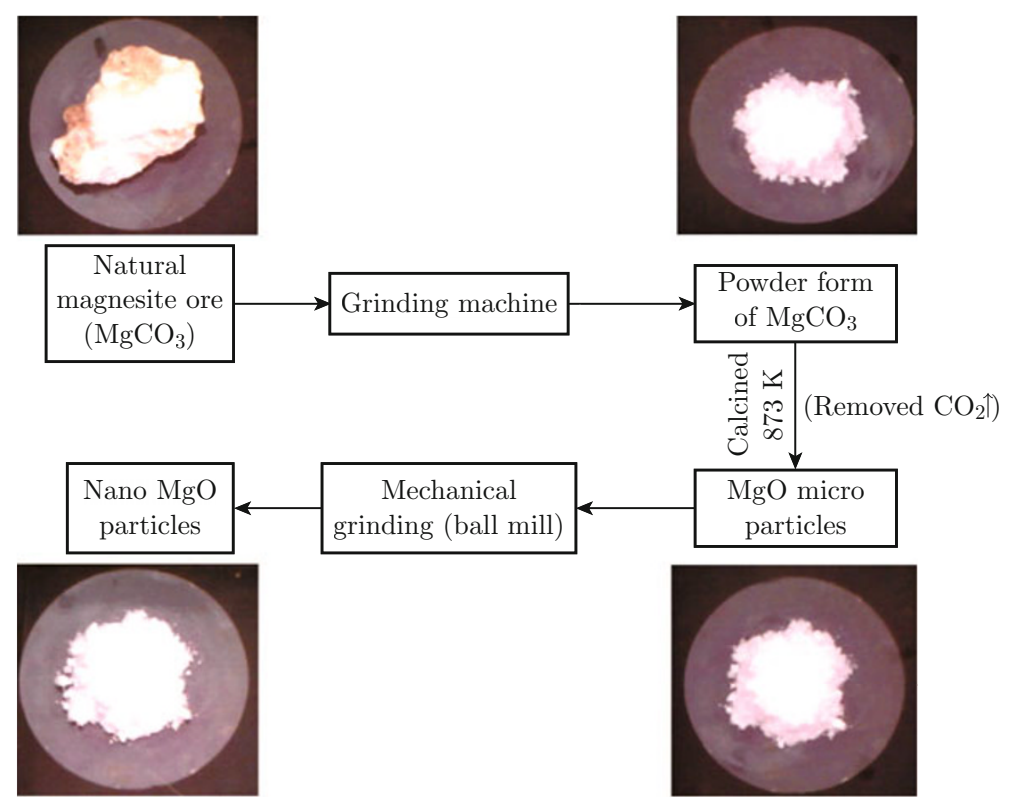

Fig. 1 Scheme for $\mathrm{MgO}$ nanoparticle preparation. 
analyzed using transmission electron microscopy (TEM; JEM-2100F; JEOL, USA) along with selected area electron diffraction (SAED).

\section{Fabric substrate}

Mercerized and bleached cotton fabric was used as the textile substrate. It has a plain woven structure with $138.84 \mathrm{~g} / \mathrm{m}^{2}$ of mass, $100 \mathrm{~s}$ of warp yarn count, and $110 \mathrm{~s}$ of weft yarn count. The fabric was cut into approximately $15 \mathrm{~cm} \times 20 \mathrm{~cm}$ pieces and washed twice with $1 \mathrm{wt} \%$ of $\mathrm{NaOH}$ solution and then with de-ionized water. The cleaned cotton fabric was dried at $35^{\circ} \mathrm{C}$ for $3 \mathrm{~min}$.

\section{Coating of nanofibers on cotton fabric}

Nylon 6 pellets were dissolved in a mixture of formic acid and acetic acid with a molar ratio of $3: 1$ at a concentration of $10 \mathrm{wt} \%$. $\mathrm{MgO}$ nanoparticles (5 wt\%) were added into the prepared homogenous nylon 6 polymer solution with continuously stirring at $400 \mathrm{rpm}$ at room temperature. Then, the solution was loaded into syringe of the electrospinning machine and placed on a syringe pump at a constant feed rate of $0.09 \mathrm{~mL} / \mathrm{h}$ to fabricate Nylon 6 and $\mathrm{MgO} /$ nylon 6 hybrid functional nanofibers, as shown in Fig. 2. During the electrospinning process, the distance between Taylor cone of the needle and collector (cylindrical drum) was fixed as 18 $\mathrm{cm}$. A $0.07-\mathrm{mm}$-diameter syringe needle was positively charged using $18-\mathrm{kV}$ high-voltage power supply to spin the fiber mats. The negative terminal connected to the collector made up of cotton fabric-rolled cylindrical drum to lead to the formation of long thread with homogeneity. The nanofiber-collected drum was rotated with a constant speed of about $35 \mathrm{rpm}$ at a fixed point for uniform coating on cotton fabrics. The approximate width of the nanofibers coated on the cotton fabric is $9 \mathrm{~cm}$, which was constant throughout the experiment. When the viscous polymer solution was ejected from the Taylor cone because of the electrostatic force, the solvent was decomposed and then evaporated. A bunch of long thread was collected on the drum that was ground.
Similarly, $\mathrm{MgO} /$ nylon 6 (1:2 wt\%) hybrid nanofibers were coated on cotton fabric using the above procedure. All the experiments were carried out at room temperature. The deposited nanofibers stick on cotton fabrics was performed at $60^{\circ} \mathrm{C}$ for 1 min under a pressure of 5 $\mathrm{gf} / \mathrm{cm}^{2}$. Hereafter, the uncoated, nylon 6 -coated, and $\mathrm{MgO} /$ nylon 6-coated hybrid fabrics were respectively termed as UC, N6C, and MN6C. The nanofiber coated fabrics (N6C, MN6C) were used for further studies.

The viscosities and ionic conductivities of the prepared nylon 6 and $\mathrm{MgO} /$ nylon 6 solutions were measured using viscometer (SNB-4;hinotek, Korea) and conductivity meter (Orion 5-Star, Thermo Scientific, USA), respectively. The surface morphology and elemental analysis of nanofibers were studied using scanning electron microscopy (SEM; JED-2300; JEOL, Japan) coupled with energy dispersive spectroscopy (EDS). The diameter of nanofiber was measured using a digital image analysis software (ImageJ; NIH, Bethesda, MD, USA). To obtain the TEM image of spun nanofiber, the fiber was deposited onto copper grid using the electrospinning technique. The deposited fibers on copper grid were dried and observed by highresolution TEM (HRTEM; JEM-2100; JEOL, USA) image. Air permeability (Premier, India) of nanofibers was measured according to IS:11056-1984 and DIN 53887 standards. Tear strength was measured using the falling pendulum-type (Elmendorf) apparatus for acceptance testing machine (ETY001; Texcare, India) according to the ASTM D1424:2007. Tensile strength was measured using the strip method for taking test machine (E091; Eureka, India) in accordance with ASTM D76-99. The fire resistance property of uncoated and coated fabrics was analyzed using flame tester (Auto Flame I; Premier) at an angle of $45^{\circ}$ in accordance with ASTM D1230-97.

\section{Antibacterial activity}

Test bacteria, E. coli (ATCC 9677) and S. aureus (ATCC 6538P) obtained from the National Collection of Industrial Microorganisms (NCIM) of National Chemical Laboratory in India, were maintained in
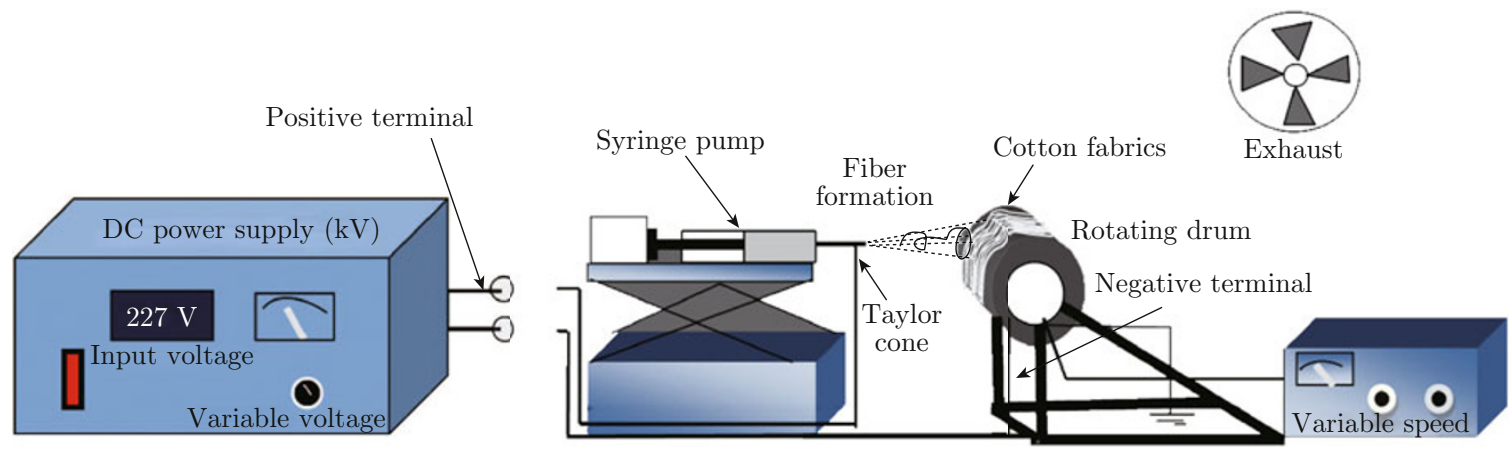

Fig. 2 Scheme for Electrospinning set-up. 
nutrient agar (HiMedia, Mumbai, India) slants at 310 $\mathrm{K}$ for $24 \mathrm{~h}$. Antimicrobial activity was screened following Kirby-Bauer method (1966) using Mueller-Hinton agar (MHA) medium (HiMedia). The MHA plates were prepared by pouring $15 \mathrm{~mL}$ molten media into sterile petri plates. The plates were allowed to solidify for about $5 \mathrm{~min}$ and a $0.1 \mathrm{~mL}$ inoculum was swabbed uniformly over the agar till becoming invisible. UC, N6C, and MN6C fabrics were loaded over the plate followed by incubation at $310 \mathrm{~K}$ for $24 \mathrm{~h}$. At the end of incubation, plates were observed for inhibition zones around the mat. Then, the inhibition zone was measured using transparent ruler (in millimeter). The study was performed in triplicates.

To evaluate the influence of $\mathrm{MgO}$ in nylon 6 nanofibers, we carried out quantitative analysis of antimicrobial activity based on the AATCC test 100-207 (AATCC 2007). The colony-forming unit (CFU) was evaluated by colony counter. Nutrient broth $(100 \mathrm{~mL})$ was prepared, and the samples named UC, N6C and MN6C were introduced. Then, the cultured $S$. aureus and $E$. coli were inoculated in the above nutrient broth followed by incubation at $37^{\circ} \mathrm{C}$ for $2 \mathrm{~h}$. After the incubation period, the inoculums from treated broth tubes were inoculated in freshly prepared nutrient agar plates followed by incubation at $37^{\circ} \mathrm{C}$ for $24 \mathrm{~h}$ and were mea-

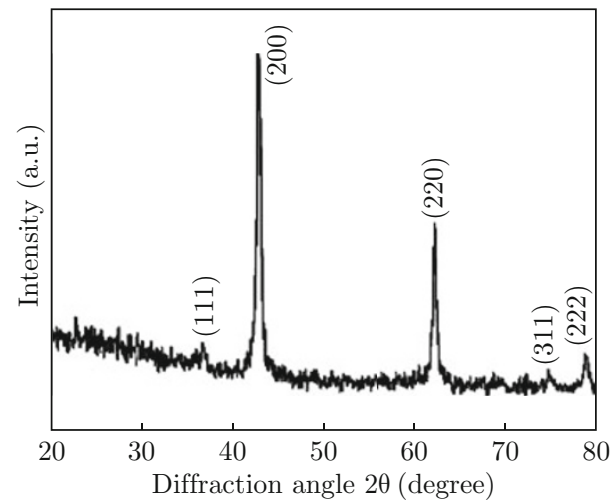

(a)

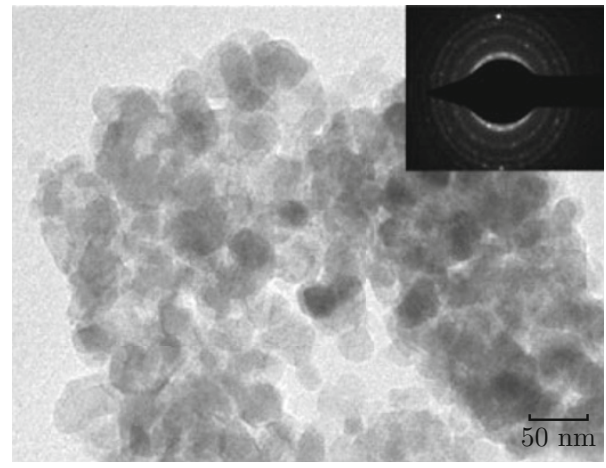

(c) sured using CFU [23].

\section{Result and discussion}

Figure 3(a) shows the powder XRD pattern of the as-prepared $\mathrm{MgO}$ nanoparticles obtained after calcinations at $600^{\circ} \mathrm{C}$. The patterns are in good agreement with the standard diffraction data of $\mathrm{MgO}$ nanoparticles (JCPDS file No. 89-7746). The broaden peaks observed at (111), (200), (220), (311) and (222) diffraction planes reveal the cubic phase of $\mathrm{MgO}$ nanoparticles. The crystallite size of $13.56 \mathrm{~nm}$ was estimated using Scherer equation.

Figure 3(b) shows the particle size distribution of the $\mathrm{MgO}$ nanoparticles in the range of $22\left(\mathrm{~d}_{10}\right)$ to $158 \mathrm{~nm}$ $\left(\mathrm{d}_{90}\right)$ and a mean diameter was about $58 \mathrm{~nm}\left(\mathrm{~d}_{50}\right)$. The particle size with short flake-like morphology was also confirmed by TEM image (Fig. 3(c)). The SAED pattern shows the concentric ring in the diffraction pattern indicating a polycrystalline structure. BET plot of $\mathrm{MgO}$ nanoparticles shown in Fig. 3(d) confirms that the SSA of $\mathrm{MgO}$ nanoparticles is $124.3 \pm 6.05 \mathrm{~m}^{2} / \mathrm{g}$.

The ionic conductivity and viscosity of nylon 6 and $\mathrm{MgO} /$ nylon 6 solutions were measured at room temperature. The obtained results indicate that the viscosity of nylon 6 solution $(107 \pm 5 \mathrm{cP})$ was higher than

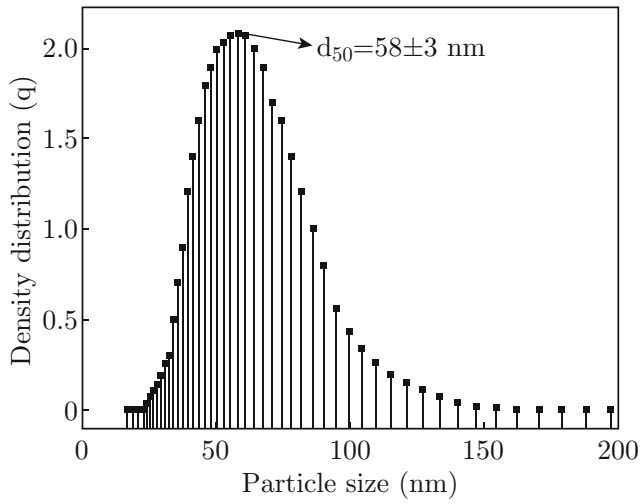

(b)

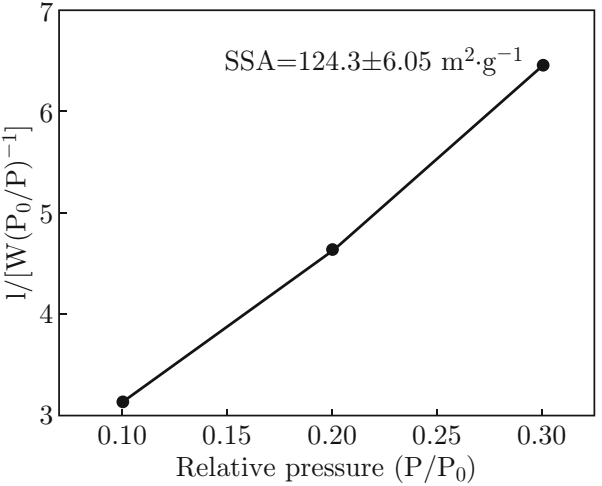

(d)

Fig. 3 Characterization of MgO nanoparticles: (a) XRD pattern; (b) particles size distribution; (c) TEM image; and (d) BET plot. 
that of the $\mathrm{MgO} /$ nylon 6 solutions $(103 \pm 5 \mathrm{cP})$. Moreover, the ionic conductivity of nylon 6 solution was increased from 3.5 to $3.8 \pm 0.1$ with addition of $\mathrm{MgO}$ nanoparticles ( $5 \mathrm{wt} \%$ ). Generally, both ionic conductivity and viscosity parameters of the polymeric solution are helpful in determining the formation of homogeneous nanofibers with controlled size [24].

The XRD patterns of UC, N6C, and MN6C fabrics are shown in Fig. 4. The diffraction peaks observed at $16.52^{\circ}, 22.82^{\circ}$ and $34.58^{\circ}$ represent the presence of cellulose on UC (Fig. 4(a)), N6C and MN6C fabrics, respectively (JCPDS file No. 3-0226) [25]. The crystalline peaks at $21.02^{\circ}$ and $24.07^{\circ}$ reveals existence of N6C fabrics (Fig. 4(b)) [26]. In Fig. 4(c) the diffraction peaks at $36.8^{\circ}, 42.8^{\circ}, 62.7^{\circ}$ and $78.7^{\circ}$, corresponding to crystal planes of (111), (200), (220) and (222) with a cubic structure of MgO (JCPDS file no. 89-7746), confirm the existence of $\mathrm{MgO}$ nanoparticle after coating on the cotton fabrics.

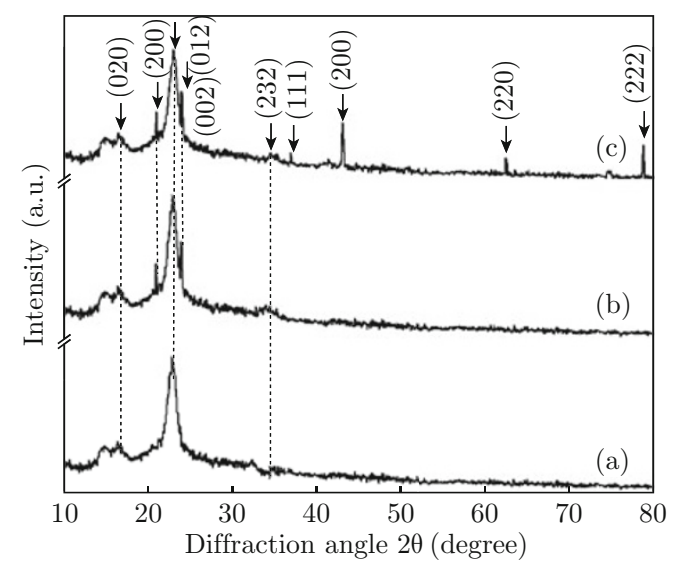

Fig. 4 XRD analysis of (a) UC fabric; (b) N6C fabrics; and (c) MN6C fabrics.

Figure 5 shows the FTIR-ATR spectra of UC, N6C and MN6C fabrics. The peaks observed at 3342, 2883 and $1458 \mathrm{~cm}^{-1}$ correspond to the stretching modes of $\mathrm{O}-\mathrm{H}$ and $\mathrm{CH}_{2}$. The peak at $1642 \mathrm{~cm}^{-1}$ reveals the bending mode of water molecules $(\mathrm{H}-\mathrm{O}-\mathrm{H})$ in all the fabrics. The band at $1107 \mathrm{~cm}^{-1}$ corresponds to the asymmetric stretching of glucose ring, whereas, the bands at 1026 and $1166 \mathrm{~cm}^{-1}$ correspond to the $\mathrm{C}-$ O stretching mode of cellulose [27]. In this study, the above observations are the same in uncoated and coated fabrics. However, the strong hydrogen bond formation of nylon 6 nanofibers and some ionic groups in cotton fabrics are confirmed from the FTIR spectra. Figure 5(b) and 5(c) show that the $\mathrm{CH}_{2}$ bond along with amide I and III peaks take respectively place at 1652 (amide I), 1202,1271 and $1363 \mathrm{~cm}^{-1}$ in N6C fabrics [6]. The peaks at $486 \mathrm{~cm}^{-1}$ in Fig. 5(c) reveal the existence of $\mathrm{MgO}$ nanoparticles in MN6C fabrics.

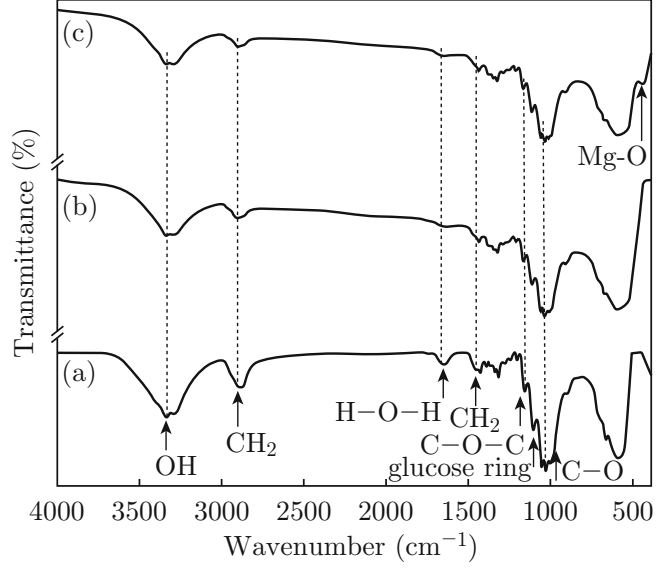

Fig. 5 FTIR-ATR analysis of (a) UC fabric; (b) N6C fabrics; and (c) MN6C fabrics.

Figure 6 shows the SEM images, size distributions and EDS patterns of nylon 6 and $\mathrm{MgO} /$ nylon 6 hybrid nanofibers, respectively. The fibers of nylon 6 is uniformity with an average diameter of $210 \mathrm{~nm}$, whereas, it is $220 \mathrm{~nm}$ for $\mathrm{MgO} /$ nylon 6 hybrid nanofibers. The diameter and homogeneity of the fibers are almost unaffected with increasing $\mathrm{MgO}$ nanoparticle concentration. The TEM images of nylon 6 nanofibers and $\mathrm{MgO} /$ nylon 6 hybrid nanofibers are shown in Fig. 7. It was found that $\mathrm{MgO} /$ nylon 6 nanofibers had a core-shell structure and $\mathrm{MgO}$ nanoparticles existed inside the cylindrical nanofibers.

Air permeability is one of the important parameters when spun nanofiber mats are used for protective applications. Generally, the fabric thickness and its porosity play a virtual role to determine the air permeability of the textile fabrics [28]. The cross-section view of N6C and MN6C fabrics is shown in Fig. 8. The air permeability values of $\mathrm{UC}, \mathrm{N} 6 \mathrm{C}$ and $\mathrm{MN} 6 \mathrm{C}$ fabrics are given in Table 1 for comparison. It can be seen that the air permeability values of MN6C fabrics are slightly less than those for N6C fabrics. However, a considerable reduction is observed in MN6C compared with UC fabrics. Normally, the air permeability of the cotton fabric decreases with increasing the thickness of the coating on fabric surface, which are in agreement with the literature report $[28,29]$.

Table 1 Physical properties of UC, N6C and MN6C fabric

\begin{tabular}{|c|c|c|c|c|c|}
\hline \multirow{2}{*}{$\begin{array}{c}\text { Sample } \\
\text { name }\end{array}$} & \multicolumn{2}{|c|}{$\begin{array}{c}\text { Tear } \\
\text { strength (gf)* }\end{array}$} & \multicolumn{2}{|c|}{$\begin{array}{l}\text { Tensile strength } \\
\text { (pounds) } \#\end{array}$} & \multirow{2}{*}{$\begin{array}{l}\text { Air permeability } \\
-\quad\left(\mathrm{cc} / \mathrm{sec} / \mathrm{cm}^{2}\right)\end{array}$} \\
\hline & $\begin{array}{l}\text { warp } \\
\text { yarn }\end{array}$ & $\begin{array}{l}\text { weft } \\
\text { yarn }\end{array}$ & $\begin{array}{l}\text { warp } \\
\text { yarn }\end{array}$ & $\begin{array}{l}\text { weft } \\
\text { yarn }\end{array}$ & \\
\hline $\mathrm{UC}$ & 440.6 & 358.8 & 92.8 & 88.6 & 84.513 \\
\hline N6C & 458.8 & 364.2 & 96.8 & 93.4 & 53.428 \\
\hline MN6C & 462.3 & 366.4 & 110.4 & 98.2 & 50.624 \\
\hline
\end{tabular}

${ }^{* \#}$ error: $\pm 0.1,{ }^{\$}$ error: \pm 0.003 


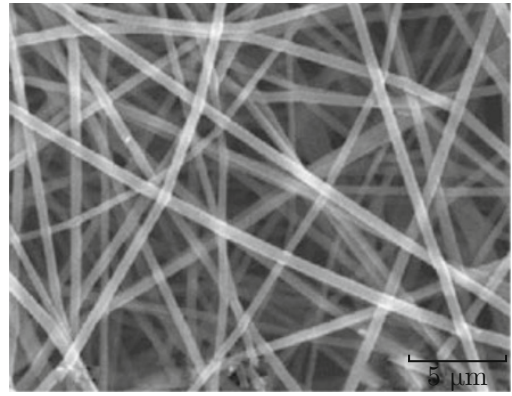

(a)

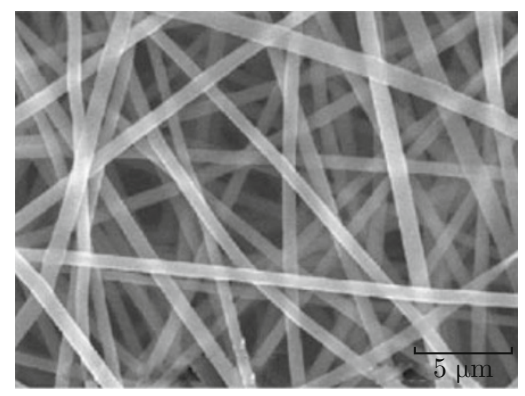

(d)

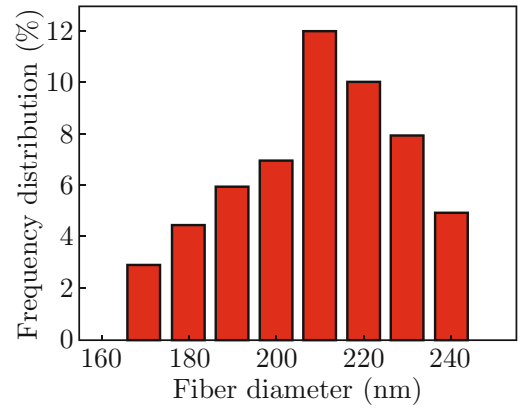

(b)

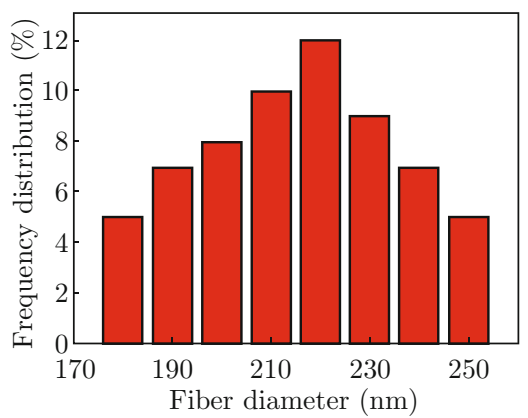

(e)

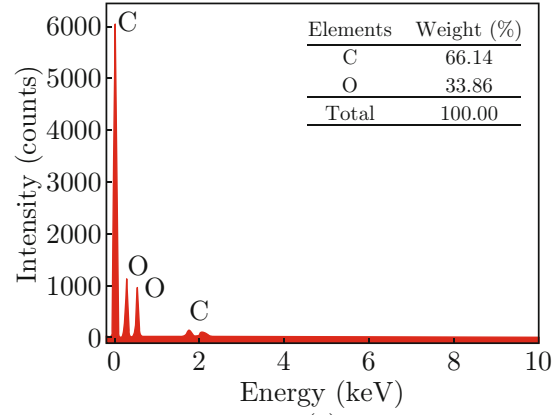

(c)

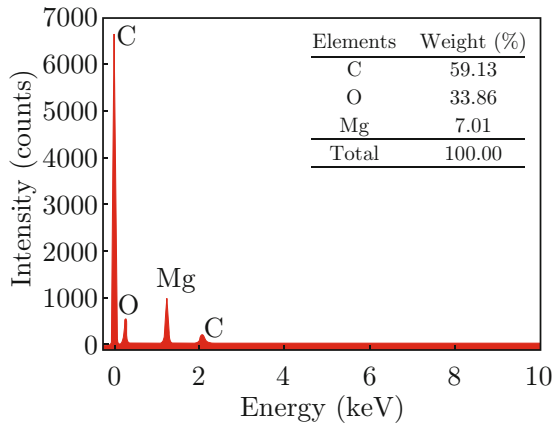

(f)

Fig. 6 SEM image, diameter distribution and EDS pattern of (a, b and c) Nylon 6 nanofiber; and (d, e and f) MgO/Nylon 6 nanofibers.
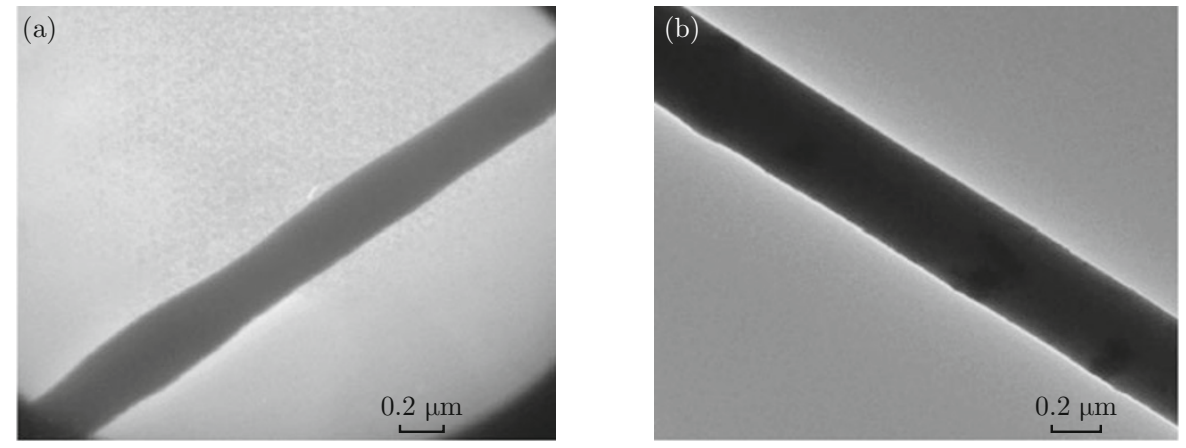

Fig. 7 TEM images shows the comparison of complex internal structure of nanofibers.

The tensile and tear strengths of UC, N6C and MN6C fabrics shown in Table 1 are both in longitudinal and transverse directions. The interstices (warp and weft yarn) values of MN6C fabrics are increased compared with those of N6C and UC fabrics. The observation is in line with our earlier studies in which the tensile and tear strengths of the nanofiber-coated cotton fabrics increased gradually due to the reduced mobility of nanofibers [30].

Average flammability test of five specimens is used to find out the flammability of UC, N6C and MN6C fabrics (shown in Fig. 9). The burning time for MN6C fabrics $(18.5 \mathrm{~s})$ is higher than that for N6C $(15.4 \mathrm{~s})$ and UC $(6.3 \mathrm{~s})$ fabrics. The increase in burning time for MN6C fabric may be due to the addition of $\mathrm{MgO}$ nanoparticles. In Fig. 9(a), some residual carbon was observed on MN6C fabrics even after testing the flame for $18.5 \mathrm{~s}$. This result confirms that addition of $\mathrm{MgO}$ nanoparticles to MN6C fabrics can enhance the flame retardancy. This observation is in line with our earlier studies that the overall flame retardancy performance of coated fabrics is higher than that of the UC fabrics $[16,31]$. Although N6C fabrics showed an increase in flame retardancy compared with UC fabrics, the observed burning time is less than that of $\mathrm{MgO}$-coated nanofabrics (MN6C).

The antimicrobial activity of $\mathrm{UC}, \mathrm{N} 6 \mathrm{C}$ and $\mathrm{MN} 6 \mathrm{C}$ fabrics is determined by the inhibition zone formed on agar plate, which is shown in Fig. 10. A significant reduction in the bacterial growth is found in MN6C fabrics than in N6C and UC fabrics by the Kirby-Bauer method [32]. The control sample of UC fabric shows no antibacterial activity (the presence of colonies is seen on the surface, thus indicating bacterial growth) against $E$. coli and $S$. aureus. The N6C and MN6C cotton fabrics placed on the bacteria-inoculated surfaces killed all the 


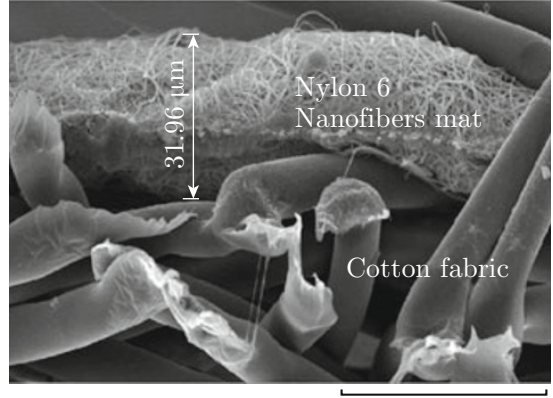

(a)

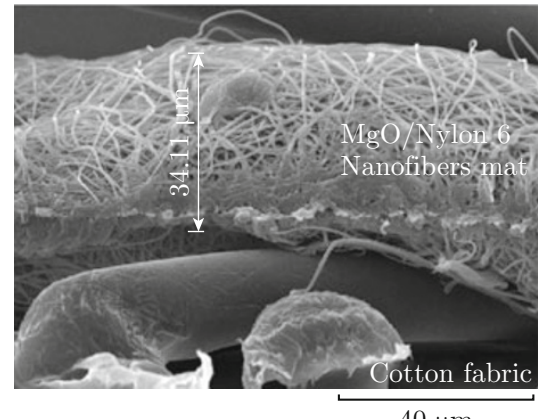

(b)

Fig. 8 The cross section view of FE-SEM image of (a) N6C; and (b) MN6C.
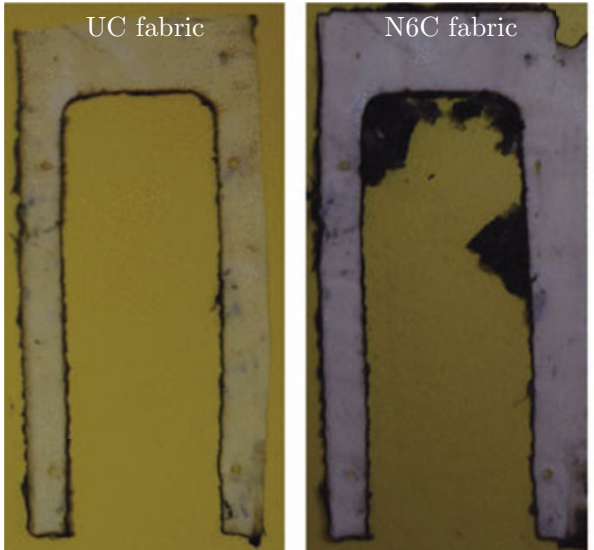

(a)

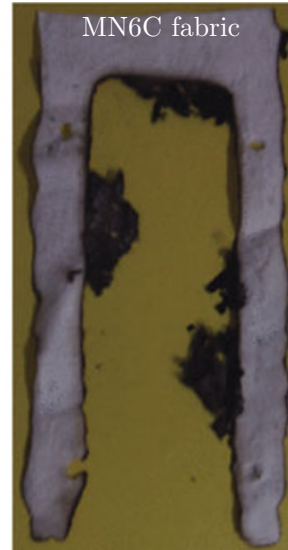

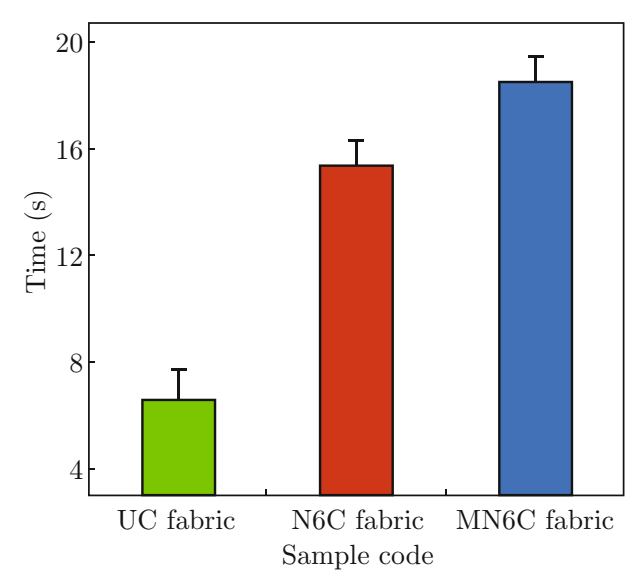

(b)

Fig. 9 (a) After burning test of uncoated and coated fabrics; (b) Average value of flammability of uncoated and coated fabrics.
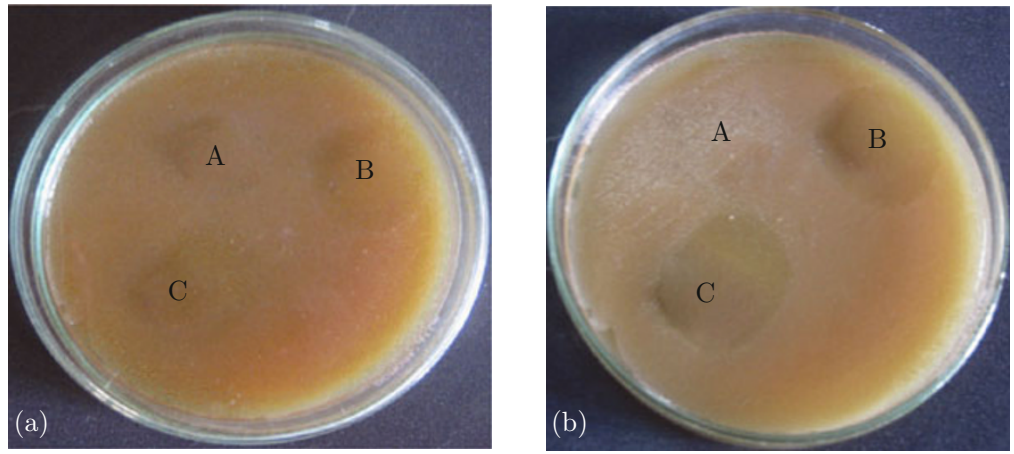

Fig. 10 Antibacterial activities of (a) Staphylococcus aureus; and (b) Escherichia coli A- UC, B- N6C and C- MN6C.

bacteria under and around the region of the fabric. It also shows the distinct zone of inhibition around $\mathrm{N} 6 \mathrm{C}$ and MN6C fabric samples for both E. coli and S. aureus. The higher antibacterial activity is attained in hybrid nanofibers (MN6C) with an inhibition zone of $18 \mathrm{~mm}$ against $S$. aureus, whereas, N6C fabrics show an inhibition zone of $12 \mathrm{~mm}$. Similarly, a large inhibition zone is formed by MN6C fabrics with a diameter of $15 \mathrm{~mm}$ against $E$. coli. Hence, the incorporation of $\mathrm{MgO}$ nanoparticles in nylon 6 nanofiber causes better antibacterial activity against both $E$. coli and $S$. aureus.
Moreover, the quantitative bacterial reduction of $\mathrm{UC}$, N6C and MN6C fabrics is also studied. The observed results are calculated by the AATCC 100 method and are tabulated in Table 2 . These results (after $24 \mathrm{~h}$ ) clearly show that the UC fabric has no reduction in the bacterial growth. The MN6C fabric shows greater bacterial reduction percentage when compared to the N6C fabric. N6C fabric shows $41 \%$ and $38 \%$ for both $S$. aureus and E. coli. The MN6C fabric shows $67 \%$ reduction against $S$. aureus and $63 \%$ reduction against $E$. coli. Among the coated fabrics, it is clearly noted that 
MN6C fiber has enhanced surface-protective properties through antibacterial activity. Thus, the broad range of antimicrobial effect is exerted by the fabrics coated with $\mathrm{MgO} /$ nylon 6 hybrid nanofibers.

Table 2 Antibacterial activity results of UC, N6C and MN6C fabric

\begin{tabular}{ccccc}
\hline \multirow{2}{*}{ Bactria } & Sample & \multicolumn{2}{c}{ No. of colonies } & \\
\cline { 3 - 4 } & name & $\begin{array}{c}\text { At '0' time } \\
\text { contact }\end{array}$ & $\begin{array}{c}\text { After } 24 \mathrm{~h} \\
\text { time contact }\end{array}$ & $(\%)$ \\
\hline Staphylococcus & $\mathrm{UC}$ & 0 & $141 \pm 0.4$ & 0 \\
aureus & $\mathrm{N} 6 \mathrm{C}$ & 0 & $82 \pm 0.2$ & 41 \\
(Gram +ve) & $\mathrm{MN6C}$ & 0 & $46 \pm 0.1$ & 67 \\
Escherichia coli & $\mathrm{UC}$ & 0 & $136 \pm 0.3$ & 0 \\
(Gram-ve) & $\mathrm{N6C}$ & 0 & $84 \pm 0.2$ & 38 \\
& $\mathrm{MN6C}$ & 0 & $51 \pm 0.1$ & 63 \\
\hline
\end{tabular}

\section{Conclusion}

The incorporation of $\mathrm{MgO}$ nanoparticles on Nylon 6 matrix was successfully carried out by an electrospinning process. The physical and functional properties of MN6C fabrics were explored and compared with those of $\mathrm{N} 6 \mathrm{C}$ and $\mathrm{UC}$ fabrics. This study confirms that MN6C fabrics have good flame resistance and antibacterial activity against Gram-negative E. coli and Grampositive $S$. aureus pathogens. The antimicrobial effects of MN6C fabrics for $S$. aureus are better than those for $E$. coli. Therefore, an enhanced flame resistance, an increased antibacterial activity, and an appropriate physical property lead to a choice of $\mathrm{MgO}$-based nylon 6 hybrid nanofibers coated on cotton fabrics for protective clothing for soldiers.

\section{Acknowledgments}

The authors acknowledge the financial support provided by the Defence Research Development Organisation (DRDO), New Delhi, for this project (ERIPR/ER/0905103/M/01/1279).

\section{References}

[1] N. Duran, P. D. Marcato, G. I. H. DeSouza, O. L. Alves and E. Esposito, "Antibacterial effect of silver nanoparticles by fungal process on textile fabrics and their effluent treatment", J. Biomed. Nanotechnol. 3(2), 203-208 (2007). http://dx.doi.org/ $10.1166 / \mathrm{jbn} .2007 .022$

[2] C. B. Giller, D. B. Chase, J. F. Rabolt and C. M. Snively, "Effect of solvent evaporation rate on the crystalline state of electrospun Nylon 6", Polymer 51(18), 4225-4230 (2010). http://dx.doi.org/ $10.1016 / j$.polymer. 2010.06 .057
[3] A. Yadav, V. Prasad, A. A. Kathe, S. Raj, D. Yadav, C. Sundaramoorthy and N. Vigneshwaran, "Functional finishing in cotton fabrics using zinc oxide nanoparticles", Bull. Mater. Sci. 29(6), 641-645 (2006). http://dx.doi.org/10.1007/s12034-006-0017-y

[4] S. Sundarrajan, A. R. Chandrasekaran and S. Ramakrishna, "An update on nanomaterials-based textiles for protection and decontamination", J. Am. Ceram. Soc. 93(12), 3955-3975 (2010). http://dx.doi. org/10.1111/j.1551-2916.2010.04117.x

[5] X. Song, Z. Liu and D. D. Sun, "Nano gives the answer: breaking the bottleneck of internal concentration polarization with a nanofiber composite forward osmosis membrane for ahigh water production rate", Adv. Mater. 23(29), 3256-3260 (2011). http://dx.doi.org/ 10.1002/adma. 201100510

[6] H. R. Pant, M. P. Bajgai, C. Yi, R. Nirmala, K. T. Nam, W. I. Baek and H. Y. Kim, "Effect of successive electrospinning and the strength of hydrogen bond on the morphology of electrospun nylon-6 nanofibers", Coll. Surf. A Physicochem. Eng. Asp. 370(1-3), 8794 (2010). http://dx.doi.org/10.1016/j. colsurfa. 2010.08 .051

[7] D. Li and Y. Xia, "Electrospinning of nanofibers: reinventing the wheel", Adv. Mater. 16(14), 115170 (2004). http://dx.doi.org/10.1002/adma. 200400719

[8] D. Li, J. T. McCann and Y. N. Xia, "Use of electrospinning to directly fabricatehollow nanofibers with functionalized inner and outer surfaces", Small 1(1), 83-86 (2005). http://dx.doi.org/10.1002/ smll. 200400056

[9] E. Jo, S. Lee, K. T. Kim, Y. S. Won, H. S. Kim and E. C. Cho, "Core-sheath nanofibers containing colloidal arrays in the core for programmable multi-agent delivery", Adv. Mater. 21(9), 968-972 (2009). http://dx. doi.org/10.1002/adma. 200802948

[10] M. Wei, J. Lee, B. Kang and J. Mead, "Preparation of core-sheath nanofibers from conducting polymer blends", Macromol. Rapid Commun. 26(14), 1127-32 (2005). http://dx.doi.org/10.1002/marc. 200500212

[11] J. Di, H. Chen, X. Wang, Y. Zhao, L. Jiang, J. Yu and R. $\mathrm{Xu}$, "Fabrication of zeolite hollow fibers by coaxial electrospinning", Chem. Mater. 20 (11), 3543-3545 (2008). http://dx.doi.org/10.1021/cm8006809

[12] V. Kalra, J. Lee, J. H. Lee, S. G. Lee, M. Marquez, U. Wiesner and Y. L. Joo, "Controlling nanoparticle location via confined assembly in electrospun block copolymer nanofibers", Small 4(11), 2067-2073 (2008). http://dx.doi.org/10.1002/smll.200800279

[13] G. Tang, X. Wang, R. Zhang, W. Yang, Y. Hua, L. Song and X. Gong, "Facile synthesis of lanthanumypophosphite and its application in glass-fiber reinforced Polyamide 6 as a novel flame retardant", Compos. Part A: Appl. Sci. Manuf. 54, 1-9 (2013). http:// dx.doi.org/10.1016/j. compositesa. 2013.07.001

[14] N. J. Mills, "Plastics: microstructure and engineering applications", 2nd Eds. Edward Arnold, UK, pp. 60-80 (1993). 
[15] N. A. M. Barakat, M. A. Kanjwal, F. A. Sheikh and H. Y. Kim, "Spider-net within the N6, PVA and PU electrospun nanofiber mats using salt addition: Novel strategy in the electrospinning process", Polymer 50(18), 4389-4396 (2009). http://dx.doi.org/ $10.1016 / j$.polymer. 2009.07.005

[16] A. Jaworek, A. Krupa, M. Lackowski, A. T. Sobczyk, T. Czech, S. Ramakrishna, S. Sundarrajan and D. Pliszka, "Electrostatic method for the production of polymer nanofibers blended with metaloxide nanoparticles", J. Phys.: Conf. Ser. 146, 012006-012012 (2009). http://dx.doi.org/10.1088/ 1742-6596/146/1/012006

[17] Y. Ding, P. Zhang, Y. Jiang, F. Xu, J. Yin and Y. Zuo, "Mechanical properties of nylon-6/ $\mathrm{SiO}_{2}$ nanofibers prepared by electrospinning" Mater. Lett. 63(1), 34-36 (2009). http://dx.doi.org/10.1016/j. matlet.2008.08.058

[18] S. Makhluf, R. Dror, Y. Abramovich, R. Jelinek and A. Gendanken, "Microwave-assisted synthesis of nanocrystalline $\mathrm{MgO}$ and its use as a bacteriocide", Adv. Funct. Mater. 15(10), 1708-15 (2005). http:// dx.doi.org/10.1002/adfm. 200500029

[19] D. J. Seo, S. B. Park, Y. C. Kang and K. L. Choy, "Formation of $\mathrm{ZnO}, \mathrm{MgO}$ and $\mathrm{NiO}$ nanoparticles from aqueous droplets in flame reactor", J. Nanopart. Res. 5(3), 199-210 (2003). http://dx.doi.org/10.1023/A: 1025563031595

[20] V. Stengl, S. Bakardjieve, M. Marikova and P. Bezdicka, "Magnesium oxide nanoparticles prepared by ultrasound enhanced hydrolysis of Mg-alkoxide", Mater. Lett. 57(24-25), 3998-4003 (2003). http://dx. doi .org/10.1016/S0167-577X (03) 00254-4

[21] S. Sundarrajan and S. Ramakrishna, "Fabrication of nanocomposite membranes from nanofibers and nanoparticles for protection against chemical warfare stimulants", J. Mater. Sci. 42(20), 8400-8407 (2007). http://dx.doi.org/10.1007/s10853-007-1786-4

[22] H. Fujishiro, T. Fukase and M. Ikebe, "Anomalous lattice softening at $\mathrm{X}=0.19$ and 0.82 in $\mathrm{La}_{1-x} \mathrm{Ca}_{x} \mathrm{MnO}_{3}$ ", J. Phys. Soc. Jap. 70(3), 628-631 (2001). http://dx . doi.org/10.1143/JPSJ . 70.628

[23] B. Elayarajah, R. Rajendran, C. Balakumar, B. Venkatrajah, A. Sudhakar and P. K. Janiga, "Antimicrobial synergistic activity of ofloxacin and ornidazole treated biomedical fabrics against nosocomial pathogens", Asian J. Text. 1, 87-97 (2011). http:// dx.doi.org/10.3923/ajt.2011.87.97
[24] S. Ramakrishna, K. Fujihara, W. E. Teo, T. C. Lim and Z. Ma, "An introduction to elecrtospining and nanofibers", 1st Eds., World scientific, Singapore. pp. 35-60 (2005).

[25] Y. Dong, Z. Bai, L. Zhang, R. Liu and T. Zhu, "Finishing of cotton fabrics with aqueous nano-titanium dioxide dispersion and the decomposition of gaseous ammonia by ultraviolet irradiation", J. Appl. Polym. Sci. 99(1), 286-921 (2006). http://dx.doi.org/10.1002/ app. 22476

[26] V. Vasanthan and D. R. Salem, "FTIR spectroscopic characterization of structural changes in polyamide- 6 fibers during annealing and drawing", J. Polym. Sci. Part B: Polym. Phys. 39(5), 536-547 (2001). http:// dx.doi .org/10.1002/1099-0488(20010301)39: 5\$<\$536: : AID-POLB1027\$>\$3. 0. C0;2-8

[27] J. Li, L. P. Zhang, F.Peng, J. Bian, T. Q. Yuan, F. Xu and R. C. Sun, "Microwave-assisted solvent-free acetylation of cellulose with acetic anhydride in the presence of iodine as a catalyst", Molecules 14(9), 3551-3566 (2009). http://dx.doi. org/10.3390/molecules 14093551

[28] S. S. Ugur, S. Merih and A. A.Hakan, "The fabrication of nanocomposite thin films with $\mathrm{TiO}_{2}$ nanoparticles by the layer-by-layer deposition method for multifunctional cotton fabrics", Nanotechnology 21(32), 325603-325610 (2010). http://dx.doi.org/10.1088/ 0957-4484/21/32/325603

[29] R. E. Link and H. H. Epps, "Prediction of singlelayer fabric air permeability by statistical modeling", J. Test. Eval. 24(1), 26-31 (1996). http://dx.doi. org/10.1520/JTE11285J

[30] G. S. Bhat, P. K. Jangala and J. E. Spruiell, "Thermal bonding of polypropylene nonwovens: effect of bonding variables on the structure and properties of the fabrics", J. Appl. Polym. Sci. 92(6), 3593-3600 (2004). http://dx.doi.org/10.1002/app. 20411

[31] N. Selvakumar, A. Azhagurajan, T. S. Natarajan and M. M. A. Khadir, "Flame retardant fabric systems based on electrospun polyamide/boric acid nano composite fiber", J. App. Poly. Sci. 126(2), 614-619 (2012). http://dx.doi.org/10.1002/app. 36640

[32] J. M. Andrews, J. C. Sherris and M. Turch, "BSAC standardized disc susceptibility testing method", J. Antimicrob. Chemother. 48(1), 43-57 (2001). http:// dx.doi.org/10.1093/jac/48.suppl_1.43 